\title{
Studi Resonansi Feromagnetik BaFe12019 Menggunakan Simulasi Mikromagnetik
}

\author{
(Study of Ferromagnetic Resonance BaFe12O19 Using Micromagnetic Simulation)
}

\author{
Angga Wicaksono, Lutfi Rohman, Edy Supriyanto \\ Jurusan Fisika, Fakultas Matematika dan Ilmu Pengetahuan Alam, Universitas Jember (UNEJ) \\ Jln. Kalimantan 37, Jember 68121 \\ E-mail: anggawicaksono9@gmail.com
}

\begin{abstract}
Abstrak
Barium Hexaferit (BaFe12O19) adalah magnet keramik golongan ferit. Ferit diaplikasikan sebagai magnet permanen dan mempunyai struktur hexagonal close-pakced (HCP). Kurva histerisis magnet permanen jenis ini memiliki koersivitas yang relatif tidak besar sehingga senyawa tersebut juga berpeluang cukup baik untuk diaplikasikan sebagai media penyimpanan data (magnetic recording) berupa patterned media. Penelitian ini mengkaji sifat-sifat magnetik bahan BaM berbentuk hexagonal terhadap kurva histerisis dan sifat resonansi feromagnetik pada berbagai variasi ukuran (meliputi : ketebalan dan diagonal hexagonal). Running simulasi mikromagnetik dilakukan untuk mendapatkan kurva histerisis dan frekuensi resonansi bahan BaM. Frekuensi resonansi meningkat (heksagonal diagonal tetap pada $12 \mathrm{~nm}$ ) dengan bertambahnya ketebalan bahan $\mathrm{BaM}$ (misal pada ketebalan $24 \mathrm{~nm}$ diperoleh frekuensi resonansi sebesar 21,7 GHz dan pada ketebalan 36 $\mathrm{nm}$ diperoleh frekuensi resonansi sebesar $22,4 \mathrm{GHz}$ ), hal ini dikarenakan dengan bertambahnya ukuran ketebalan bahan $\mathrm{BaM}$ posisi spin terlihat sangat teratur. Sedangkan hubungan frekuensi resonansi dengan diagonal hexagonal yaitu kebalikannya.
\end{abstract}

Kata Kunci: BaFe12O19, Simulasi mikromagnetik, Frekuensi resonansi

\begin{abstract}
Barium Hexaferrite (BaFe12O19) is a class of ceramic ferrite magnet. Ferrite was applied as a permanent magnet and it has hexagonal close-pakced structure (HCP). Hysterisis curve of this type of permanent magnet has t relatively large coercivity, so it was applied as a data storage medium (magnetic recording) in the patterned media form. This research studied the magnetic property of BaM material shaped hexagonal of the hysteresis curve and resonance ferromagnetic properties in a variety of sizes (including: the thickness and hexagonal diagonal). The Micromagnetic simulations has run to get hysteresis curve and resonance frequency of BaM material. The resonance frequency is increased (the hexagonal diagonal fixed at $12 \mathrm{~nm}$ ) by the increasing of thickness of BaM material (ex; the thickness of $24 \mathrm{~nm}$ is obtained resonance frequency of $21.7 \mathrm{GHz}$ and the thickness of $36 \mathrm{~nm}$ is obtained resonance frequency of $22.4 \mathrm{GHz}$ ), the spin position of BaM material, due it looks very organized. While the relationship of resonance frequency with hexagonal diagonal to be opposite.
\end{abstract}

Keywords: BaFe12O19, Micromagnetic simulation, Resonance frequency

\section{PENDAHULUAN}

Penelitian tentang magnet telah banyak dilakukan untuk mengetahui karakteristik sifat magnet. Salah satunya contohnya adalah magnet keramik bersifat magnetik mencangkup golongan ferit. Ferit dikenal dengan magnet keramik yang biasanya diaplikasikan sebagai magnet permanen yang mempunyai struktur hexagonal closepakced (HCP). Salah satu contoh bahan magnet keramik golongan Ferit adalah Barium Hexaferit (BaFe12O19). Barium Hexaferit dikelompokan menjadi 5 tipe yaitu tipeM (BaFe12O19), tipe-W (BaMe2Fe16O27), tipe-X (Ba2Me2Fe28O46), tipe-Y (Ba2Me2Fe12O22) dan tipe-Z (Ba2Me2Fe24O41). Tipe-M biasanya dikenal dengan barium hexaferrite yang biasa disebut BaM [2].

Karakteristik suatu material feromagnetik dapat dilihat dari besar medan koersivitas (Hc) kurva histerisisnya. Besar koersivitas menentukan magnet tergolong pada jenis softmagnetic atau hard-magnetic. Untuk bahan yang memiliki koersivitas yang besar (Hc> $1 \mathrm{kA} / \mathrm{m})$ disebut hard- magnetic, sedangkan untuk bahan yang memiliki koersivitas kecil $(\mathrm{Hc}<1 \mathrm{kA} / \mathrm{m})$ disebut soft-magnetic. Besar nilai koersivitas dapat diketahui dari kurva histerisis, yang memiliki satuan ampere-turn/meter [1].

Resonansi Feromagnetik adalah teknik utama untuk meneliti dinamika magnetisasi dari struktur magnetik. Kinerja divais berbasis magnetik dipengaruhi pembalikan magnetisasi dan FMR (ferromagnetic resonance) dapat meningkatkan kecepatan pembacaan dan penulisan data pada divais. Penelitian mengenai pembalikan magnetisasi dan FMR dipublikasikan secara ekperimen maupun simulasi dengan memberikan medan magnet luar atau sinyal pulsa [3]. Resonansi feromagnetik terjadi karena bahan magnetik berosilasi saat diberikan medan yang berosilasi secara periodik. Unjuk kerja resonansi feromagnetik ini banyak diterapkan untuk sensor magnetik dan penyerap gelombang elektromagnetik [6].

Penelitian ini menggunakan bahan Barium Hexaferit (BaFe12O19) dikenal dengan golongan Ferit tipe-M (BaM), merupakan oksida keramik yang paling banyak 
dimanfaatkan secara komersial. Kurva histerisis magnet permanen jenis ini memiliki koersivitas yang relatif tidak besar sehingga senyawa tersebut juga berpeluang cukup baik untuk diaplikasikan sebagai media penyimpanan data berupa patterned media [4].

\section{METODE PENELITIAN}

Penelitian ini dilakukan sesuai dengan diagram alir sebagai berikut.

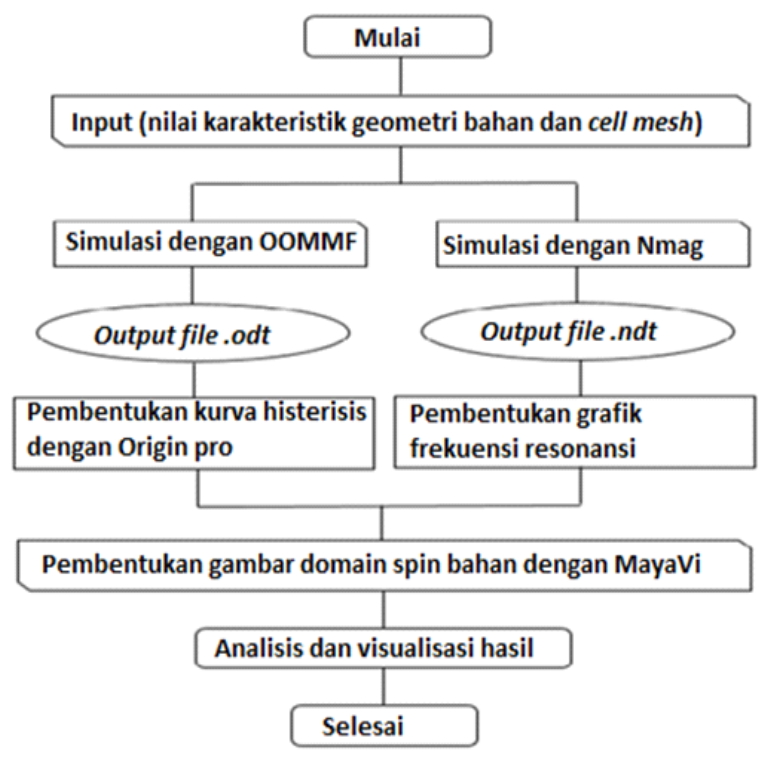

Gambar 1. Bagan tahap-tahap penelitian mendapatkan kurva histerisis dan frekuensi resonansi bahan $\mathrm{BaM}$

Parameter bahan lapisan tipis BaM untuk simulasi mikromagnetik terdiri dari: magnetisasi saturasi , konstanta exchange, dan konstanta anisotropi. Ukuran sel yang digunakan pada simulasi ini berdasarkan ukuran exchange length dari bahan ini yaitu dengan faktor redaman sebesar 0,1. Bahan BaM dalam simulasi ini menggunakan dua parameter yaitu ketebalan dan diagonal hexagonal untuk mencari kurva histerisis dan frekuensi resonansi. Pertama penelitian dilakukan untuk mencari kurva histerisis, besar ketebalan ditentukan sebesar $150 \mathrm{~nm}, 300 \mathrm{~nm}, 450 \mathrm{~nm}, 600$ $\mathrm{nm}$ dan $750 \mathrm{~nm}$ sedangkan besar diagonal hexagonal ditentukan sebesar $50 \mathrm{~nm}$ dan $100 \mathrm{~nm}$. Bahan BaM memiliki geometri berbentuk hexagonal dengan berbagai variasi ketebalan dengan diberi medan eksternal quasistatic yang diberikan ke arah hard-axis dari -2000 mT sampai $2000 \mathrm{mT}$ dengan kenaikan (increment) $10 \mathrm{mT}$ ukuran sel sebesar ( 5 x 5 x 10 ) nano meter kubik. Kedua penelitian dilakukan untuk mencari frekuensi resonansi, besar ketebalan ditentukan sebesar $24 \mathrm{~nm}, 36 \mathrm{~nm}, 48 \mathrm{~nm}$, $60 \mathrm{~nm}, 72 \mathrm{~nm}, 84 \mathrm{~nm}, 96 \mathrm{~nm}, 120 \mathrm{~nm}, 156 \mathrm{~nm}, 180 \mathrm{~nm}$ dan besar diagonal hexagonal digunakan adalah12 nm untuk variasi ketebalan. Sedangkan untuk variasi diagonal hexagonal, besar diagonal hexagonal ditentukan sebesar 12 $\mathrm{nm}, 24 \mathrm{~nm}, 48 \mathrm{~nm}, 96 \mathrm{~nm}$ dan besar ketebalan adalah 12 $\mathrm{nm}$. Bahan yang digunakan kali ini adalah hard-magnet berupa BaFe12O19 (Barium Hexaferrite). Parameter yang digunakan dalam memberikan karakteristik bahan antara lain, magnetisasi saturasi (Ms) sebesar $275 \mathrm{kA} / \mathrm{m}$, konstanta exchange(A) sebesar $2 \times 10 \mathrm{e}-11 \mathrm{~J} / \mathrm{m}$, konstanta anisotropi (K) sebesar 9,6x10e4 J/meter kubik, dan exchange length (Iexc) sebesar 20,52 nm.

\section{HASIL PENELITIAN}

\section{Resonansi Feromagnetik ( FMR )}

FMR adalah teknik utama untuk meneliti dinamika magnetisasi dari struktur magnetik. Frekuensi resonansi bahan feromagnetik dapat diukur secara eksperimen menggunakan alat FMR. Kinerja FMR dipengaruhi oleh proses pembalikan magnetisasi. Resonansi Feromagnetik dalam nanoelemen telah banyak dipublikasikan baik secara eksperimen maupun secara simulasi dengan memberikan medan magnet luar atau sinyal pulsa. Hasil penelitian Resonansi Feromagnetik diperoleh frekuensi resonansi dalam rentang $\mathrm{GHz}$ menggunakan simulasi mikromagnetik [3]. Pada tabel 1 memperlihatkan besarnya frekuensi FMR berdasarkan penelitian hasil simulasi dan berdasarkan perhitungan Kittel sebagai acuan dalam menentukan frekuensi FMR berbagai ketebalan bahan BaM pada diagonal hexagonal $12 \mathrm{~nm}$.

Berdasarkan perhitungan Kittel dimana semakin besar ketebalan bahan maka frekuensi FMR yang diperoleh semakin besar sehingga besar ketebalan sebanding dengan Frekuensi FMR. Pada gambar nampak saat rasio 2 pada hasil simulasi didapatkan frekuensi resonansi sebesar 21,7 $\mathrm{GHz}$ sedangkan berdasarkan perhitunggan Kittel diperoleh sebesar 21,9 GHz. Hasil selengkapnya diperlihatkan dalam Tabel 1.

Tabel 1. Besar Frekuensi FMR dari berbagai ketebalan pada diagonal hexagonal $12 \mathrm{~nm}$

\begin{tabular}{cccc}
\hline No & $\begin{array}{c}\text { Rasio } \\
(\mathrm{h} / \mathrm{D})\end{array}$ & $\begin{array}{c}\text { Frekuensi FMR } \\
\text { dalam simulasi } \\
(\mathrm{GHz})\end{array}$ & $\begin{array}{c}\text { Frekuensi FMR dalam } \\
\text { perhitungan kittel ( GHz })\end{array}$ \\
\hline 1 & 2 & 21,7 & 21,9 \\
2 & 3 & 22,4 & 22,8 \\
3 & 4 & 22,8 & 23,3 \\
4 & 5 & 23,1 & 23,6 \\
5 & 6 & 23,3 & 23,8 \\
6 & 7 & 23,4 & 23,9 \\
7 & 8 & 23,5 & 24 \\
8 & 10 & 23,6 & 24,1 \\
9 & 13 & 23,7 & 24,2 \\
10 & 15 & 23,8 & 24,3 \\
\hline
\end{tabular}

Hasil simulasi yang dipaparkan pada tabel 1 selanjutnya dibuatkan grafik hubungan frekuensi FMR dengan berbagai ketebalan bahan BaM pada diameter $12 \mathrm{~nm}$ sebagaimana ditunjukkan pada Gambar 2. Pada Gambar 2 diperoleh informasi bahwa semakin besar ketebalan bahan BaM maka frekuensi FMR yang diperoleh semakin besar, sehingga nilai ketebalan sebanding dengan frekuensi FMR hal ini dikarenakan dengan bertambahnya ukuran ketebalan bahan BaM maka posisi spin terlihat sangat teratur. Penelitian sebelumnya telah dilakukan juga oleh Dita Oktri (2013) dengan memakai bahan BaM, dengan menggunakan perhitungan Kittel sebagai acuannya untuk mencari diameter krisis dari BaM. Penelitian FMR (Feromagnetic 
Resonance) bahan BaM yaitu untuk menemukan frekuensi resonansi disetiap ukuran yang diteliti dengan menggunakan simulasi mikromagnetik dan persamaan Kittel sebagai acuan awalnya sebelum melakukan simulasi. Persamaan Kittel digunakan sebagai pendekatan teorinya dalam membandingkan hasil simulasi FMR dengan teori.

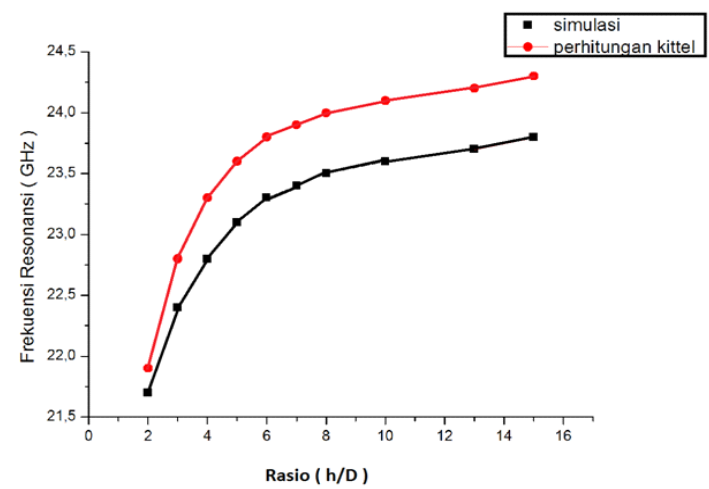

Gambar 2. Hubungan frekuensi FMR dengan berbagai ketebalan pada diagonal hexagonal $12 \mathrm{~nm}$ berdasarkan simulasi dan perhitungan Kittel

Gambar 3 memperlihatkan hubungan Frekuensi FMR dengan berbagai diagonal hexagonal bahan BaM pada ketebalan $12 \mathrm{~nm}$ dimana memiliki arti fisis yaitu semakin besar diameter (ketebalan tetap) maka frekuensi resonansi diperoleh semakin kecil karena posisi spin terlihat tidak teratur dan tidak jelas saat bertambahnya ukuran diameter bahan BaM.

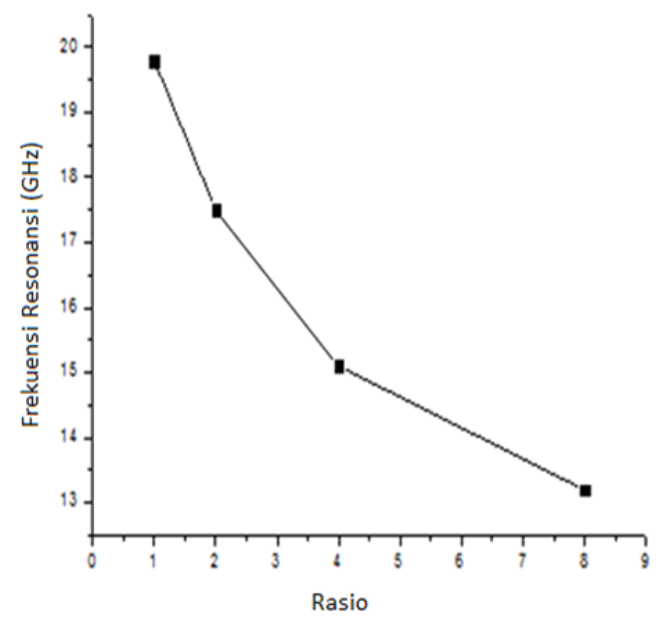

Gambar 3. Hubungan frekuensi FMR dengan diagonal hexagonal bahan BaM pada ketebalan $12 \mathrm{~nm}$

Pada Tabel 2 memperlihatkan besarnya frekuensi FMR berdasarkan berbagai diameter bahan BaM pada ketebalan $12 \mathrm{~nm}$. Pada rasio 1 diperoleh frekuensi resonansi sebesar 19,8 GHz. Semakin besarnya diameter bahan BaM diperoleh frekuensi resonansi relatif menurun hal ini dapat disimpulkan bahwa besar diameter berbanding terbalik dengan frekuensi resonansi yang diperoleh.

Tabel 2. Besar Frekuensi FMR dari berbagai diagonal hexagonal pada ketebalan $12 \mathrm{~nm}$

\begin{tabular}{|c|c|c|c|c|}
\hline $\mathrm{N}$ & & Rasio ( D/h ) & \multicolumn{2}{|c|}{ Frekuensi FMR (GHz) } \\
\hline 1 & & 1 & \multicolumn{2}{|c|}{19,8} \\
\hline 2 & & 2 & \multicolumn{2}{|c|}{17,5} \\
\hline 3 & & 4 & \multicolumn{2}{|c|}{15,1} \\
\hline 4 & & 8 & \multicolumn{2}{|c|}{13,2} \\
\hline Sampel & & Lokasi & $\begin{array}{l}\text { Konduktivitas } \\
(\mu \mathrm{S} / \mathrm{cm})\end{array}$ & $\begin{array}{c}\text { Konsentrasi } \\
\mathrm{Fe}^{3+} \text { dalam } \\
\text { sampel (ppm) }\end{array}$ \\
\hline $\mathrm{C}$ & & e arahutara & 713,491 & 0,439 \\
\hline D & & e arah barat & 254,436 & 0,114 \\
\hline E & & e arah selatan & 243,450 & 0,122 \\
\hline $\mathrm{F}$ & & ke arah selatan & 241,537 & 0,146 \\
\hline G & & ke arah selatan & 269,769 & 0,163 \\
\hline $\mathrm{H}$ & & ke arah selatan & 240,777 & 0,122 \\
\hline I & & ke arahutara & 265,491 & 0,130 \\
\hline $\mathrm{J}$ & & ke arahutara & 259,890 & 0,187 \\
\hline
\end{tabular}

\section{KESIMPULAN}

Berdasarkan hasil penelitian diperoleh kesimpulan bahwa hubungan frekuensi FMR dengan ketebalan yaitu semakin besar ketebalan bahan BaM (diagonal hexagonal tetap yaitu $12 \mathrm{~nm}$ ) maka semakin besar frekuensi resonansinya (misal pada ketebalan $24 \mathrm{~nm}$ diperoleh frekuensi resonansi sebesar $21,7 \mathrm{GHz}$ dan pada ketebalan $36 \mathrm{~nm}$ diperoleh frekuensi resonansi sebesar 22,4 GHz), hal ini dikarenakan dengan bertambahnya ukuran ketebalan bahan BaM posisi spin terlihat sangat teratur. Sedangkan hubungan frekuensi FMR dengan diagonal hexagonal yaitu semakin besar diagonal hexagonal (ketebalan tetap yaitu 12 nm) maka frekuensi resonansi diperoleh semakin kecil (misal pada diagonal hexagonal $12 \mathrm{~nm}$ diperoleh frekuensi resonansi sebesar $19,8 \mathrm{GHz}$ dan pada diagonal hexagonal $24 \mathrm{~nm}$ diperoleh frekuensi resonansi sebesar 17,5 GHz) karena posisi spin terlihat tidak teratur dan tidak jelas saat bertambahnya ukuran diameter bahan BaM.

\section{DAFTAR PUSTAKA}

[1] Carter, C. Barry, dan M. G. Norton. 2007. Ceramic Materials: Science and Engineering Springer.

[2] Darminto, M. Zainuari, dan E. I. Kamariyah. 2011. Sintesis Serbuk Barium Hexaferrite Dengan metode Kopresipitasi. Seminar Nasional Pascasarjana XIITS, Surabaya, 27 Juli 2011, Jurusan Fisika FMIPA.

[3] Liu , Z. 2007. Magnetization dynamic in the presence of nanoscale spatial inhomogeneity, Department of Physics, Edmonton, Fall.

[4] Nowosielski, R., R. Babilas, G. Derecz, L. Pajak, dan J. Wrona. 2007. Structure and Porperties of Barium Ferrite Powders Prepared by Milling and Annealing. Archives of Materials Science and Engineering. Vol. 28, Issue. 12, pp. $735-742$.

[5] Oktari, D. 2013. Studi perilaku magnetik $\mathrm{BaFe}_{12} \mathrm{O}_{19}$ berbentuk hexagonal dengan menggunakan simulasi mikromagnetik. Skripsi. Depok: FMIPA-UI.

[6] Rohman, L. 2013. Investigasi Sifat-sifat Magnetik Bahan LSMO $\left(\mathrm{La}_{1-\mathrm{x}} \mathrm{Sr}_{\mathrm{x}} \mathrm{MnO}_{3}\right)$ untuk Aplikasi Storage Device dengan Menggunakan Modeling Mikromagnetik. Laporan Hibah Doktor, Jember: UNEJ. 